\title{
Creep Crack Growth Prediction Using a Damage Based Approach $^{\dagger}$
}

\author{
M. Yatomi, K. M. Nikbin, N. P. O’Dowd \\ Department of Mechanical Engineering \\ Imperial College London \\ South Kensington Campus, \\ London, SW7 2AZ, UK
}

\begin{abstract}
This paper presents a numerical study of creep crack growth in a fracture mechanics specimen. The material properties used are representative of a carbon-manganese steel at $360^{\circ} \mathrm{C}$ and the constitutive behaviour of the steel is described by a power law creep model. A damage-based approach is used to predict the crack propagation rate in a compact tension specimen and the data are correlated against an independently determined $C^{*}$ parameter. Elastic-creep and elastic-plastic-creep analyses are performed using two different crack growth criteria to predict crack extension under plane stress and plane strain conditions. The plane strain crack growth rate predicted from the numerical analysis is found to be less conservative than the plane strain upper bound of an existing ductility exhaustion model, for values of $C^{*}$ within the limits of the present creep crack growth testing standards. At low values of $C^{*}$ the predicted plane stress and plane strain crack growth rates differ by a factor between 5 and 30 depending on the creep ductility of the material. However, at higher loads and $C^{*}$ values, the plane strain crack growth rates, predicted using an elastic-plastic-creep material response, approach those for plane stress. These results are consistent with experimental data for the material and suggest that purely elastic-creep modelling is unrealistic for the carbon-manganese steel as plastic strains are significant at relevant loading levels.
\end{abstract}

Keywords: Creep, crack growth, finite element analysis, multiaxiality, damage, constraint

\section{Introduction}

Many components used in power generation plants are continually exposed to high temperatures and failure processes such as net section rupture, creep crack growth or fatigue crack growth can occur within the high temperature regime. Safe and accurate methods to predict creep crack growth (CCG) are therefore required in order to assess the reliability of such components. With advances in finite element (FE) methods, more complex models can be applied in the study of CCG where simple analytical solutions or approximate methods are no longer applicable. In this work the role of fracture mechanics parameters in estimating creep crack growth rates is examined using FE analysis and the results are validated with experimental data.

\footnotetext{
${ }^{\dagger}$ To appear in the International Journal of Pressure Vessels and Piping, 2003
} 
Hayhurst et al. [1] were among the first to carry out finite element calculations using a Kachanov-type [2] damage variable to account for the evolution of creep damage within the material. While these studies focused on uncracked structures (notched bars), the approach has also been used to estimate creep damage and rupture life in cracked components, e.g. [3]-[9]. In many of these studies, e.g. [1], [3], [8], special procedures have been used to remove elements within the FE mesh which have reached a critical level of damage. The loss of load bearing capacity due to creep damage within the element is thus accounted for. However, it is well known that the use of a coupled damage approach in conjunction with element removal can lead to a mesh sensitive result, e.g. [10], [11]. Furthermore, the removal of elements may not accurately model the situation where a sharp crack is growing within a creeping material. In this work therefore an alternative approach is adopted whereby nodes ahead of the crack tip are released when the damage reaches a critical value. A similar node-release approach to model crack growth under creep conditions has been employed in recent work, [12] and [13]. However, in [12], [13] the crack growth rate has been assumed a priori, based on experimental data, and has not been determined within the analysis. Therefore the approach cannot be used for the prediction of creep crack growth and rupture life.

In the present study a damage variable, based on the equivalent (von Mises) creep strain rate and the Cocks and Ashby void growth model [14], is used to predict creep crack growth in a compact tension (CT) fracture specimen within an FE framework. The creep parameter, $C^{*}$, which is independently determined from the numerically calculated loadline displacement rate, is used to correlate the predicted crack growth data. In addition, a sensitivity analysis of the CCG predictions is presented, to identify the effects of mesh size and relevant elastic-plastic and creep material properties. Both plane stress and plane strain conditions are examined.

\section{Material data}

\subsection{Uniaxial creep properties}

The material properties for the carbon manganese $(\mathrm{C}-\mathrm{Mn})$ steel at $360^{\circ} \mathrm{C}$ were obtained from uniaxial tensile tests and creep tests [15]. The details of the material composition and the relevant mechanical properties are given in Table 1 and Table 2 respectively. The material batch chosen in this study has been designated as a high nitrogen content $\mathrm{C}-\mathrm{Mn}$ steel. This alloy has been previously shown to be more brittle under creep conditions than a corresponding low nitrogen C-Mn steel [15]. 
A representative creep curve (creep strain vs. time) is shown in Figure 1. In general, creep deformation can be considered to be composed of three regimes, namely primary, secondary and tertiary creep regimes. The use of an average creep rate obtained directly from creep rupture data has been proposed [16] to account for all three stages of creep. This average creep rate, $\dot{\varepsilon}_{A}$, is described schematically in Figure 1 and is defined by

$$
\dot{\varepsilon}_{A}=\frac{\varepsilon_{f}}{t_{r}}=\dot{\varepsilon}_{o}\left(\frac{\sigma}{\sigma_{0}}\right)^{n_{A}}=A_{A} \sigma^{n_{A}},
$$

where $\varepsilon_{f}$ is the uniaxial failure strain, $t_{r}$ is the time to rupture and $\sigma$ is the applied stress. The variables $\dot{\varepsilon}_{o}, \sigma_{o}, A_{A}$ and $n_{A}$ in equation (1) are generally taken as material constants, though as illustrated below they may depend on stress.

Figure 2 and Figure 3 show the dependence of $\dot{\varepsilon}_{A}$ and $\varepsilon_{f}$ respectively on stress for the C-Mn steel determined from constant load creep tests on round bars [15]. It may be seen in Figure 2 that the creep exponent, $n_{A}$, defined by equation (1), is not constant at a given temperature but increases with stress. The values of $A_{A}$ and $n_{A}$ used in the analysis are shown in Table 2, which are the ones most relevant to the test conditions being examined (relatively low stress and strain rate). Figure 3 shows the dependence of uniaxial creep failure strain, $\varepsilon_{f}$, on stress for the steel at $360^{\circ} \mathrm{C}$. It is seen that within the scatter of the data $\varepsilon_{f}$ is independent of stress. Due to the observed scatter the numerical analysis was performed using the mean value of the creep failure strain and the upper and lower bound values (mean $\pm 2 s$ (where $s$ is the standard deviation)) estimated as $18 \%, 26 \%$ and $10 \%$ respectively. In addition, for the purposes of a sensitivity analysis, analyses with failure strain equal to $50 \%$ were also carried out.

\subsection{High Temperature Fracture Mechanics}

The theory behind the correlation of high temperature crack growth data essentially follows that of elastic-plastic fracture mechanics theory. Various aspects of the characterisation of creep crack growth have been reviewed in [17] and [18].

For situations where elasticity dominates (short times and/or high loads) the linear elastic stress intensity factor, $K$, may be used to predict crack growth. Under steady state conditions, however, the crack tip stress and strain rate fields are characterised by the parameter $C^{*}$ and linear elasticity may no longer be applicable. For a power law creeping material, the stress and strain rate in the vicinity of the crack tip are given by (see e.g. [17]), 


$$
\begin{aligned}
& \sigma_{i j}=\sigma_{0}\left(\frac{C^{*}}{\dot{\varepsilon}_{0} \sigma_{0} I_{n} r}\right)^{1 /(n+1)} \widetilde{\sigma}_{i j}(\theta, n), \\
& \dot{\varepsilon}_{i j}=\dot{\varepsilon}_{0}\left(\frac{C^{*}}{\dot{\varepsilon}_{0} \sigma_{0} I_{n} r}\right)^{n /(n+1)} \widetilde{\varepsilon}_{i j}(\theta, n),
\end{aligned}
$$

where $r$ and $\theta$ measure distance and polar angle relative to the crack tip, $I_{\mathrm{n}}$ is a parameter which depends only on the creep exponent, $n$, and $\widetilde{\sigma}_{i j}$ and $\widetilde{\varepsilon}_{i j}$ are dimensionless functions. The parameter $C^{*}$ in equation (2) may be obtained from a path independent integral and is analogous to the $J$ integral for rate independent material behaviour [19]. $C^{*}$ may also be interpreted as an energy release rate analogous to the energy definition of $J$, i.e.,

$$
C^{*}=-\frac{1}{B} \frac{d U^{*}}{d a}
$$

where $a$ is the crack length, $B$ is the thickness and $U^{*}$ is the potential energy rate. The $C^{*}$ integral has been widely used as a parameter for correlating CCG under steady state creep conditions [20].

Based on the form of the crack tip fields in equation (3) and using a ductility exhaustion argument it was shown in [21], [22], that the creep crack growth rate, $\dot{a}$, may be written as,

$$
\dot{a}=\frac{(n+1) \dot{\varepsilon}_{0}}{\varepsilon_{f}^{*}}\left(\frac{C^{*}}{I_{n} \sigma_{0} \dot{\varepsilon}_{0}}\right)^{n /(n+1)} r_{c}^{1 /(n+1)},
$$

where $r_{c}$ is the size of the creep process zone and $\varepsilon_{f}^{*}$ is the appropriate crack tip ductility, (taken as the uniaxial failure strain, $\varepsilon_{f}$, for plane stress and $\varepsilon_{f} / 30$ for plane strain [23]). This model, known as the NSW model, was shown to provide good agreement with measured CCG rates for a range of materials. The cracking rate $\dot{a}$ in equation (4) can be written in simplified form as

$$
\dot{a}=D C^{* \phi},
$$

where $D$ and $\phi$ are material constants, with $\phi=n /(n+1)$ from the NSW model and the value of $D$ depends on the uniaxial creep properties and the appropriate failure strain $\varepsilon_{f}^{*}$.

\subsection{Creep Crack Growth Testing and Analysis}

In laboratory tests, rather than use the line integral definition or equation (3) directly, $\mathrm{C}^{*}$ may be determined from the creep load-line displacement rate. Following ASTM E145701 [20] $C^{*}$ is given by the following equation: 


$$
C^{*}=\frac{P \dot{\Delta}^{c}}{B_{n} b} F,
$$

where $P$ is the applied load, $b$ is the remaining ligament ahead of the crack and $B_{n}$ is the net thickness ( $=B$ for a specimen without side grooves). The factor, $F$, in equation (6) depends on geometry and creep exponent, $n$. For a CT specimen $F$ is given by

$$
F=\frac{n}{n+1}[2+0.522(1-a / W)]
$$

where $a$ is crack length and $W$ the specimen width. In equation (6) $\dot{\Delta}^{c}$ is the load-line creep displacement rate and is calculated as follows:

$$
\dot{\Delta}^{c}=\dot{\Delta}^{T}-\dot{\Delta}^{e}-\dot{\Delta}^{p},
$$

where $\dot{\Delta}^{T}, \dot{\Delta}^{e}$ and $\dot{\Delta}^{p}$ are the total, elastic and plastic displacement rates respectively. The contribution to the total displacement rate from the elastic displacement rate, $\dot{\Delta}^{e}$, is due to the change in crack length and an equation for $\dot{\Delta}^{e}$ is provided in ASTM E1457-01 [20]. Creep crack growth testing is normally carried out at loads where plastic deformation is insignificant [17] and it is assumed that $\dot{\Delta}^{c} \gg \dot{\Delta}^{p}$. Hence the creep strain rate can be calculated as [20]

$$
\dot{\Delta}^{c}=\dot{\Delta}^{T}-\dot{\Delta}^{e} \text {. }
$$

The creep crack growth behaviour of the C-Mn steel at $360^{\circ} \mathrm{C}$, obtained from tests on CT specimens of different sizes and analysed according to ASTM E1457-01 [20], is shown in Figure 4 (taken from [15]). These data will be used to validate the finite element models presented in this paper.

The data in Figure 4 show no apparent size effect during steady state creep crack growth behaviour within the examined sizes $(W=15,25$ and $50 \mathrm{~mm}$ ) and the cracking rate $\dot{a}$ can therefore be characterized by $C^{*}$. A mean fit to the data is shown in Figure 4 using equation (5) with $D=4.70 \times 10^{-5}$ and $\phi=0.89\left(C^{*}\right.$ in $\mathrm{J} / \mathrm{m}^{2} \mathrm{~h}$ and $\mathrm{d} a / \mathrm{d} t$ in $\mathrm{mm} / \mathrm{h}$ ). (Note that this value of $\phi$ is consistent with the relationship that $\phi=n / n+1)$. Also included in the figure are the upper and lower bounds of the CCG rate based on the mean $\pm 2 s$.

\section{Finite Element Modelling}

\subsection{Damage accumulation}

In this work a ductility exhaustion approach is used to account for the accumulation of creep damage. The damage parameter, $\omega$, is defined such that $0 \leq \omega \leq 1$ and failure occurs 
when $\omega$ approaches 1 . The rate of damage accumulation, $\dot{\omega}$ is related to the equivalent creep strain rate by the relationship,

$$
\dot{\omega}=\frac{\dot{\varepsilon}^{c}}{\varepsilon_{f}^{*}}
$$

and the total damage at any instant is the integral of the damage rate in equation (10) up to that time:

$$
\omega=\int_{0}^{t} \dot{\omega} d t
$$

Thus, failure occurs in the vicinity of the crack tip when the local accumulated strain reaches the local (multiaxial) creep ductility. Assuming that the mechanism of creep crack growth is by void coalescence, then the multiaxial creep ductility, $\varepsilon_{f}^{*}$, can be obtained from a number of available void growth models (e.g. [14], [24] and [25]). It has been found that the Cocks and Ashby model [14] is the most appropriate for representing the multiaxial creep ductility of the material under study. The model describes the ratio of the multiaxial to uniaxial failure strain, $\varepsilon_{f}^{*} / \varepsilon_{f}$ as

$$
\frac{\varepsilon_{f}^{*}}{\varepsilon_{f}}=\sinh \left[\frac{2}{3}\left(\frac{n-1 / 2}{n+1 / 2}\right)\right] / \sinh \left[2\left(\frac{n-1 / 2}{n+1 / 2}\right) \frac{\sigma_{m}}{\sigma_{e}}\right],
$$

where $\sigma_{m} / \sigma_{e}$ is the ratio between the mean (hydrostatic) stress and equivalent (von Mises) stress. This ratio is often referred to as the triaxiality. Note that within an FE analysis the value of $\varepsilon_{f}^{*}$ changes for a fixed material point since it depends on the triaxiality through equation (12), which, as will be seen, changes with time as the stress redistributes local to the crack tip.

\subsection{Elastic, plastic and creep strains}

Calculations have been performed using elastic-creep and elastic-plastic-creep behaviour. In the latter case the plastic strains are understood to be independent of strain rate giving the total strain as

$$
\varepsilon=\varepsilon^{e l}+\varepsilon^{p l}+\varepsilon^{c r},
$$

where, $\varepsilon^{e l}, \varepsilon^{p l}$ and $\varepsilon^{c r}$ are elastic, plastic and creep strains respectively. As discussed in Section 2.1 the creep response is described by a secondary creep law using the average creep properties. The yield strength of the steel at $360^{\circ} \mathrm{C}$ is $240 \mathrm{MPa}$ (see Table 2) which 
is relatively low, so the effect of plasticity may be important for this material. The plastic response is assumed to be governed by a Mises flow rule with isotropic strain hardening and was obtained by fitting to uniaxial tensile test data at $360^{\circ} \mathrm{C}$. The post-yield strain hardening response is treated as piece-wise linear up to the UTS $(=570 \mathrm{MPa})$ beyond which no strain hardening occurs. For an elastic-creep analysis or during unloading the plastic strain rate is zero.

\subsection{Finite Element Framework}

A two dimensional FE model of a CT specimen with $W=25 \mathrm{~mm}, B=12.5 \mathrm{~mm}$ and $a / W=0.45$ is examined. Two different meshes for the CT specimen are used (see Figure 5 ) in order to examine the influence of mesh size. For the coarse mesh in Figure 5(a) the mesh size at the crack tip is $0.25 \mathrm{~mm}$, while for the fine mesh in Figure 5(b) the mesh size at the crack tip is approximately $0.0154 \mathrm{~mm}$, which is similar to the grain size of the C-Mn steels examined. All finite element analyses were conducted using ABAQUS 5.8 [26] and a typical coarse mesh contains 602 four noded elements while the fine mesh contains 7581 four noded elements. Full account is taken in the analysis of large displacements and rotations, due to, e.g., the blunting of the initially sharp crack tip.

Two methods for modelling crack extension were considered. The first, which will be identified as the fixed-node model, considers that the crack has propagated when damage, $\omega$, as derived from equations (10)-(12), reaches 0.999 at two integration points ahead of the crack tip. There is no change in the boundary conditions and the damage parameter simply acts as an indicator to locate the position of the crack tip as damage spreads throughout the specimen. In the second method, identified as the node-release model, the node at the crack tip is released when $\omega$ reaches 0.999 and as a result the crack propagates through the mesh along the axis of symmetry.

Figure 6 shows a schematic illustration of the node release method. It is assumed that the crack grows in the plane of the initial crack front, i.e. along the symmetry plane. The model therefore assumes a sharp fronted flat crack, which idealises the actual condition of multiple microscopic cracks linking up ahead of the main crack front. A user subroutine (MPC) which allows the user to alter nodal constraints during the analysis, was used to release the nodes. Within this subroutine, the $y$-displacement at a node is held fixed until the node is to be released and, subsequent to the release, the constraint in the $y$-direction is no longer applied. In the crack growth analysis the maximum extent of crack growth is determined by the mesh design (crack grows through a region of uniform sized elements 
as shown in the inset to Figure 5(b)). With this mesh design the maximum amount of crack growth is approximately $3.75 \mathrm{~mm}$ (i.e. $0.33 a$ ) for both fine and coarse mesh design.

Table 3 provides a complete list of the FE runs carried out using different combinations of material properties and conditions. The results from these analyses are discussed in section 4.

\section{$4 \quad$ Finite Element Results}

A typical result from a node-release analysis is illustrated in Figure 7, which shows the total load-line displacement obtained from the FE analysis compared with two experimental results. Tertiary creep behaviour (rapid increase in displacement towards the end of the test) is predicted by the finite element analysis, due to the reduction in area caused by cracked growth. It is seen that the experimental data generally lie between the plane stress and plane strain predictions. The creep load-line displacement data from the numerical analysis is subsequently used to calculate the parameter $C^{*}$ using equation (6). The FE results can then be compared directly with the experimental CCG results shown in Figure 4.

Figure 8 illustrates damage contours for the node-release method, in a typical plane strain analyses. The 'wake' of creep damage behind the current crack tip may be seen in the figure. The relatively uniform size and shape of the region suggests that crack growth is occurring within the steady state regime for this analysis.

The rate of accumulation of damage depends strongly on the triaxiality, $\sigma_{m} / \sigma_{e}$, through equation (12). Under plane stress conditions it has been found from the FE analysis that $\sigma_{m} / \sigma_{e}$ is relatively insensitive to the distance ahead of the crack tip, while under plane strain conditions $\sigma_{m} / \sigma_{e}$ varies with distance from the crack tip and also depends on the extent of crack growth. As an example Figure 9 shows the variation of $\sigma_{m} / \sigma_{e}$ with distance from the crack tip under plane stress and plane strain conditions using the noderelease method. The average values for $\sigma_{m} / \sigma_{e}$ from these analyses are 0.6 and 2.5 for plane stress and strain respectively. Similar values for crack tip triaxiality $\sigma_{m} / \sigma_{e}$ were found in [27] and the values are consistent with the theoretical crack tip distributions of equation (2) (see e.g. [28]). (Note however that equation (2) predicts that $\sigma_{m} / \sigma_{e}$ is independent of distance from the crack tip $r$, implying the zone of dominance of the HRR solution may be very small for the plane strain case). The implications of this strong 
difference in crack tip triaxiality between plane stress and plane strain conditions will be seen in the subsequent sections.

\subsection{Comparison between fixed-node and node-release models of CCG}

The difference in the predicted increase in crack length $(\Delta a)$ with time for the two models of crack extension is examined in this section. The coarse mesh shown in Figure 5(a) was used and elastic-creep analyses for plane stress and plane strain conditions were conducted. Figure 10 shows the amount of crack growth predicted by the fixed-node and the node-release model under plane stress and strain conditions when the applied load is $9 \mathrm{kN}$. The experimental data are also included on the figure. Since the first data point for the coarse mesh will be at $\Delta a=0.25 \mathrm{~mm}$ (the smallest element size) the finite element results are extrapolated back to the initial crack length $(\Delta a=0)$ using the slope of the predicted curve at $\Delta a=0.25 \mathrm{~mm}$. This provides a more realistic representation of the initiation period before crack growth occurs.

It is seen in Figure 10 that the amount of crack growth predicted by the node-release model is greater than that from the fixed-node model, particularly under plane strain conditions, and is also closer to the experimental data (as might be expected). However in all cases the predicted amount of crack growth is less than that observed in the experiments, so both models are non-conservative. By comparing Figure 10(a) and (b) it can be seen that the predicted rate of crack growth under plane strain conditions is initially higher than that for plane stress conditions (predicted crack growth is negligible under plane stress conditions for time, $t<6 \times 10^{3}$ hours). However the crack growth rate under plane stress conditions becomes higher for $t>6 \times 10^{3}$ hours. A possible explanation for this behaviour is that the stress and strain distributions for plane strain conditions are more localised than those for plane stress conditions (see Figure 9). Therefore although the damage in the element at the crack tip accumulates faster for plane strain conditions than for plane stress conditions, the damage accumulates more slowly in the second and third elements from the crack tip, leading to an overall faster rate of crack growth under plane stress at the same load.

\subsection{Effects of mesh size and crack tip plasticity in the node-release model}

In the previous section, it was found that the node-release model gives better agreement with the experimental data than the fixed-node model. In this section, the effect of mesh size and crack tip plasticity on the predictions from the node-release model are examined. 
The predicted increase in crack length with time for each analysis is shown in Figure 11. Both coarse and fine meshes have been examined, under plane stress and plane strain conditions with and without plastic deformation. It is seen that in all cases reducing the mesh size leads to an increase in the rate of crack growth for both plane stress and plane strain conditions. (Note that the difference in mesh size between the coarse and fine mesh is more than an order of magnitude). Thus, using the nodal release method does not eliminate the effect of mesh size on crack growth predictions. The increase in crack growth rate with decreasing mesh size is due to the increased stress and strain in the vicinity of the crack tip for the fine mesh. Therefore, particularly for plane strain conditions, the time for the damage at the crack tip to reach 0.999 is much shorter and the crack extends much more quickly. It is seen however, that the use of the fine mesh produces a more conservative result - the predicted crack growth rates for the fine mesh in Figure 11(a) and (b) are higher than the experimental values. The effects of plastic deformation are examined in Figure 11(c) and (d). It can be seen that the inclusion of crack tip plasticity leads to a decrease in the amount of crack growth at the same load, particularly for the fine mesh analysis. This is because the crack tip stresses at short times are reduced due to plastic deformation and the creep strain rates are therefore also reduced. It has also been found that under plane strain conditions the crack tip triaxiality is also reduced when plasticity is included. Since plastic strains do not contribute to creep damage (see equation (10)) the overall effect is a reduction in the amount of crack growth for the same applied load. It is also clear from Figure 11 that the effect of plasticity is less significant for the coarse mesh-for the coarse mesh the stress levels at the crack tip are not sufficient to lead to significant amounts of plastic strain.

It can be seen in Figure 11 that the mesh size effect is more significant for the elastic analysis than the elastic-plastic analysis. This is to be expected, as plastic deformation will reduce the high stress concentration at the sharp crack tip in the fine mesh. Thus the inclusion of plastic strains tends to mitigate the effect of mesh size and reduce the conservatism of the fine mesh analysis leading (in this case) to an underprediction of the crack growth rate. However, the excellent agreement between the plane stress elasticplastic model and the experimental data (Figure 11(c)) is noted.

\subsection{Predicted CCG rate under plane stress and plane strain conditions}

In this section the ability of the creep parameter $C^{*}$ to characterise the CCG rate is examined. The fine mesh was used and both plane stress and plane strain conditions were 
examined. The upper-bound value of $\varepsilon_{f}(=50 \%)$ is used, which results in a relatively slow crack growth rate and ensures that transient effects are relatively small (i.e. crack growth occurs under predominantly steady state conditions).

Figure 12 shows the CCG rate predictions plotted against $C^{*}$ using an elastic-creep and an elastic-plastic-creep response. Here $C^{*}$ was calculated from the load line displacement rate as discussed in section 2.3 and the transient parts of the crack growth curves (the 'tails') have been removed for each analysis so only results under (global) steady state conditions are presented. The dash lines in Figure 12 are a linear fit to the elastic-creep plane stress and plane strain results. In order to cover a wide range of $C^{*}$ values, two simulations were run for each case analysed, a low load case, $P=5 \mathrm{kN}$ and a high load case, $P=7 \mathrm{kN}$. It can be seen from Figure 12 that under plane stress conditions there is little difference in the CCG rate predicted by the elastic-creep and the elastic-plastic-creep analysis. It may also be seen that for an elastic-creep analysis, the predicted CCG rate under plane strain conditions is consistently higher than for plane stress by a factor of about 5 (as indicated by the dotted lines in the figure). However for an elastic-plasticcreep analysis when $C^{*}>20 \mathrm{~J} / \mathrm{m}^{2} \mathrm{~h}$, the plane strain $\mathrm{CCG}$ rate predictions converge towards the plane stress result. This behaviour is somewhat unexpected as the NSW model, [21] and [22], predicts that plane strain crack growth rates should be higher than plane stress crack growth rates at the same value of $C^{*}$.

In order to confirm that the observed behaviour is not due to inaccuracies in the load-line method for estimating $C^{*}$ from equation (6) the $\mathrm{FE}$ data were replotted using the line integral value for $C^{*}$ obtained directly from the $\mathrm{FE}$ analysis. The value of $C^{*}$ was averaged over five remote contours for each crack increment and was found to be almost path independent once steady state conditions had been reached (the difference is about $15 \%$ over the five contours). Figure 13 shows the CCG rate plotted against the two estimates of $C^{*}$ for an elastic-plastic creep analysis. It is clear from the figure that the same trends are observed for the CCG rate regardless of the method used to estimate $C^{*}$. It should however be noted that for higher values of $C^{*}\left(C^{*}>10 \mathrm{~J} / \mathrm{m}^{2} \mathrm{~h}\right)$, the line integral estimates of $C^{*}$ are slightly lower than those obtained from equation (6). This small difference could be due to the increasing magnitude of the plastic strain rate $\dot{\Delta}^{p}$ at higher values of $C^{*}$ which has been included in the estimation of $\dot{\Delta}^{c}$ (using equation (9)) when calculating $C^{*}$ from equation (6). At lower values of $C^{*}$ the effects of plasticity are insignificant and the correlation between the two methods is better. It should be noted that 
the effect of plastic strain on the value of $C^{*}$ is small (as shown in Figure 13) and therefore equation (9) provides a good estimation of creep strain rate in this study suggesting that $\dot{\Delta}^{c} \approx \dot{\Delta}^{T}-\dot{\Delta}^{e}$.

\subsection{Comparison between experimental and predicted CCG rate}

In this section the $\mathrm{d} a / \mathrm{d} t v s . C^{*}$ curves obtained from the $\mathrm{FE}$ analysis are compared with the experimental data. The mean value of uniaxial failure strain, $\varepsilon_{f}=18 \%$, has been used in the analyses in order to allow direct comparison with the data. Elastic-plastic-creep analyses were conducted using the fine mesh.

Figure 14 shows the CCG rate from the FE analysis plotted against $C^{*}$. As in Figure 12, $C^{*}$ has been calculated from the predicted load line displacement rate. The experimental data band taken from Figure 4 is also shown in the figure. For the elastic-plastic analysis a similar trend to that seen in Figure 12 is observed - the predicted plane strain CCG rate converges towards the plane stress predictions at high values of $C^{*}$.

As previously stated, in the region where the relatively short term experimental data are obtained there is little effect on the CCG rate due to specimen size (see Figure 4). This is consistent with the predicted CCG rates in Figure 14 (i.e. the same response for plane stress and plane strain analyses at high values of $C^{*}$ ). The mean values of $\sigma_{m} / \sigma_{e}$ from Figure 9 are approximately 0.6 and 2.5, for plane stress and plane strain conditions respectively. If these values are used in equation (12) the values obtained for $\varepsilon_{f P E}^{*}$ (plane strain) and $\varepsilon_{f}^{*}$ (plane stress) are

$$
\varepsilon_{f P E}^{*} \approx \frac{1}{72} \varepsilon_{f} \text { and } \varepsilon_{f P S}^{*} \approx \frac{1}{2} \varepsilon_{f}
$$

Thus the FE analysis suggests that a factor of 30 between the plane stress and strain failure strain as recommended in [23] is appropriate. Also taking into account the different values of $I_{n}$ under plane strain and plane stress conditions, equation (4) implies a factor of about 24 between the plane strain and plane stress CCG rate. However, while this difference in crack growth rate between plane strain and plane stress is indeed predicted by the FE analysis at low values of $C^{*}$, it is not seen at higher values (see Figure 13 and Figure 14).

The ASTM E1457-01 [20] bounds for CCG testing in terms of the load-line creep displacement rate divided by the load-line total displacement rate $\left(\dot{\Delta}^{c} / \dot{\Delta}^{T}\right)$ are included in Figure 14. For convenience the notation $\dot{\bar{\Delta}}=\dot{\Delta}^{c} / \dot{\Delta}^{T}$ is used. In [20] in order to characterise 
CCG by $C^{*}$, it is required that $\dot{\bar{\Delta}}>0.5$. It is also suggested in [20] that for $\dot{\bar{\Delta}}<0.25$, the linear elastic stress intensity factor $K$ may be applicable. The NSW predictions, equation (4), are shown in Figure 14 taking $\varepsilon_{f}^{*}=\varepsilon_{f}$ for plane stress and $\varepsilon_{f}^{*}=\varepsilon_{f} / 30$ for plane strain [23]. Comparing the finite element results to the predictions of the NSW model and disregarding the limits set by ASTM E1457-01 [20], there is a good comparison between the CCG rate bounds of the FE and the NSW model at low values of $C^{*}$ (where elasticcreep conditions hold). Furthermore, there is good agreement over the full range of $C^{*}$ between the NSW plane stress prediction and the plane stress FE result.

\subsection{Effect of Creep Failure Strain on CCG Rate}

In this section, the effect of creep failure strain on the CCG rate is examined. For these analyses $\varepsilon_{f}=10 \%, 18 \%, 26 \%$, and $50 \%$. The first three values for failure strain are the lower, mean and upper bound of the failure strain for the C-Mn steel as shown in Figure 3 and the case $\varepsilon_{f}=50 \%$ was included to represent a more ductile material.

Figure 15 shows the comparison of predicted relative displacement rate, $\dot{\bar{\Delta}}$, against $C^{*}$ for the different values of $\varepsilon_{f}$. As can be seen in Figure 15, for plane stress conditions, the values of $\dot{\bar{\Delta}}$ for all failure ductilities are significantly above 0.5 . However, for plane strain conditions and low values of $C^{*}, \dot{\bar{\Delta}}$ can be below 0.5 , particularly for the lower creep ductility. A reduction in creep ductility leads to an increase in the crack growth rate and a corresponding increase in $\dot{\Delta}^{e}$ and thus a decrease in $\dot{\bar{\Delta}}$. This suggests that for a brittle material (low $\varepsilon_{f}$ ), high constraint levels (plane strain) and low loads (low $C^{*}$ ), CCG cannot be correlated using $C^{*}$. For ductile materials (high $\varepsilon_{f}$ ), $\dot{\bar{\Delta}}>0.5$ and CCG will be characterised by $C^{*}$.

Figure 16(a) shows FE predictions of plane stress CCG rate versus $C^{*}$ for the highest and lowest creep ductilities and compares the results with the individual predictions lines from the plane stress NSW model (equation (4)). Similar behaviour has been seen for the other two creep ductilities. It is clear that the FE elastic-plastic-creep crack growth rate prediction is approximately the same as the NSW model using the appropriate failure ductility, when $C^{*}>0.2 \mathrm{~J} / \mathrm{m}^{2} \mathrm{~h}$. The equivalent results for plane strain conditions are illustrated in Figure 16(b). In this case the results for all four values of failure strain are included. It may be seen that although the predicted crack growth rates are significantly different at low values of $C^{*}$, at higher $C^{*}$ values the FE predictions converge towards the 
plane stress lines (compare data in Figure 16(a) and (b)) and the difference in crack growth rate is reduced.

The values of CCG rate are plotted as hollow symbols in Figure 16(b) for $\dot{\bar{\Delta}}>0.5$, as grey symbols for $\dot{\bar{\Delta}}<0.5$ and in black for $\dot{\bar{\Delta}}<0.25$. It can be seen that in all cases the upper-bound (plane strain) NSW prediction is conservative when $\dot{\bar{\Delta}}>0.5$ (i.e. the NSW model predicts faster CCG rates than the FE analysis) and the model remain conservative (though less so) provided $\dot{\bar{\Delta}}>0.25$. This suggests that the CCG rate can also be safely correlated by $C^{*}$ and the NSW upper bound prediction in the region $0.25<\dot{\bar{\Delta}}<0.5$. This region generally corresponds to conditions of low stress and could be described as a transition region between creep ductile and creep brittle conditions. Note that the value of $\dot{\bar{\Delta}}$ used here includes the contribution from the plastic displacement rate and therefore the true value of $\dot{\bar{\Delta}}$ is slightly smaller. This further suggests that the present ASTM transition limit of 0.5 for $C^{*}$ characterisation [20] is somewhat conservative and could safely be lowered.

\section{Discussion and Conclusions}

This paper presents methods for predicting creep crack growth in a CT specimen, using a damage variable to quantify time dependent crack tip degradation. The material examined is a carbon-manganese steel at a test temperature of $360{ }^{\circ} \mathrm{C}$. A power law creep model is used to describe the constitutive behaviour of the steel and both plane stress and plane strain conditions are examined using the finite element method. The predicted CCG rate is correlated using the creep parameter $C^{*}$ determined from the load-line displacement rate. The effect of mesh size, crack tip plasticity and uniaxial failure ductility, $\varepsilon_{f}$, on the creep crack growth rate were examined and found to have a stronger influence under plane strain conditions than under plane stress conditions.

The results obtained from the analyses suggest that for this material the effect of crack tip plasticity cannot be ignored over the full loading range. When plastic strains are included, it is found that at high values of $C^{*}$ the predicted plane strain crack growth rate approaches that for plane stress whereas at low loads they differ by a factor of $\sim 5-30$ depending on the creep ductility. The convergence of the plane stress and plane strain predictions at high values of $C^{*}$ is believed to be due to the reduction in constraint level in the plane strain geometry caused by plastic deformation. The trend is consistent with the 
experimental observation of little effect of specimen size on CCG at high values of $C^{*}$ for this material. Laboratory CCG testing times are usually between 1,000 and 5,000 h giving values of $C^{*}$ usually in excess of $1 \mathrm{~J} / \mathrm{m}^{2} \mathrm{~h}$. On the other hand, component used in plant are exposed to creep conditions at lower stresses for periods of $10^{4}-10^{5} \mathrm{~h}$ leading to values of $C^{*}<<1 \mathrm{~J} / \mathrm{m}^{2} \mathrm{~h}$ for most components. The FE results therefore suggest that the prediction of component life using the data band from short-term experimental tests may not be sufficiently conservative.

It is also observed that provided $\dot{\bar{\Delta}}>0.25$ the predicted finite element $\mathrm{CCG}$ rates at low loads $\left(C^{*}<1 \mathrm{~J} / \mathrm{m}^{2} \mathrm{~h}\right)$ are consistent with the predictions using the NSW ductility exhaustion model, over a wide range of failure ductilities, although it is found that the NSW model is considerably more conservative. This suggests that the limits of $\dot{\bar{\Delta}}$, as defined by ASTM E1457-01 [20], which disallows the use of $C^{*}$ at $\dot{\bar{\Delta}}<0.5$ may need to be re-examined for long term test conditions of more brittle materials. Additional experimental investigations to derive more accurate creep properties and the use of detailed creep constitutive equations are needed to validate these findings further.

\section{References}

[1] Hayhurst, D.R., Dimmer, P.R. and Morrison, C.J., 'Development of continuum damage in the creep rupture of notched bars,' Phil. Trans. R. Soc. Lond. A 1984; 311,103-129

[2] Kachanov, L.M., 1986, 'Introduction to Continuum Damage Mechanics', Kluwer Academic Publishers, Dordrecht

[3] Hayhurst, D.R., Brown, P.R. and Morrison, C.J., 'The role of continuum damage in creep crack growth', Phil. Trans. R. Soc. Lond. A 1984; 311, 131-158

[4] Hyde, T.H., Xia, L. and Becker, A.A., 'Prediction of creep failure in aero-engine materials under multi-axial stress states’, Int. J. Mech. Sci. 1996; 38, 385-403.

[5] Hyde, T.H., Sun, W. and Becker, A.A., 'Creep crack growth in welds: a damage mechanics approach to predicting initiation and growth of circumferential cracks', Int. J. of Press. Vess. And Pip. 2001; 78, 765-771

[6] Bellenger, E. and Bussy, P., 'Phenomenological modelling and numerical simulation of different modes of creep damage evolution', Int. J. Sol. and Str. 2001; 38, 577-604 
[7] Hall, F.R. and Hayhurst, D.R., 'Continuum damage mechanics modelling of high temperature deformation and failure in a pipe weldment', Proc. R. Soc. Lond. A $1991 ;$ 433, 383-403

[8] Perrin, I.J., and Hayhurst, D.R., 'Continuum damage mechanics analyses of type IV creep failure in ferritic steel cross-weld specimens', Int. J. Pres. Vess. and Piping. 1999; 76, 599-617

[9] Bassani, J.L. and Hawk, D.E., 'Influence of damage on crack-tip fields under smallcreep conditions', Int. J. of Fracture. 1990; 42, 155-172

[10] Murakami S., Liu. Y. and Mizuno M.' Computational methods for creep fracture analysis by damage mechanics', Computing Methods Appl. Mech. Engrg. 2000; $183,15-33$

[11] Yatomi, M., O’Dowd, N. P., Nikbin, K. M. 'Modelling of damage development and failure in notched bar multiaxial creep tests' submitted for publication

[12] Zao, L.G., Tong, J., Byrne, J., 'Finite element simulation of creep-crack growth in a nickel base super alloy', Eng. Frac. Mech.2001, 68, 1157-1170

[13] Saxena, A., Hall, D.E., McDowell, D.L., 'Assessment of deflection rate partitioning for analysing creep crack growth data', Eng. Frac. Mech., 1999; 62, 111-122

[14] Cocks, A.C.F. and Ashby, M.F., 'Intergranular fracture during power-law creep under multiaxial stress', Metal Science 1980; 14, 395-402.

[15] Maskell, R. V., Fleming, A., Crawford, P. J. and Buchanan, L. W., 'Creep crack growth in internally pressurised tubes', J. Materials at High Temperature, 1998;15(3/4) 151-158.

[16] Nikbin, K.M., Smith, D.J. and Webster, G.A., 'Prediction of creep crack growth from uniaxial creep data', Proc. Roy. Soc. London, A 1984; 396, 183-197.

[17] Webster, G.A. and Ainsworth, R.A. 1994, 'High Temperature Component Life Assessment', Chapman and Hall.

[18] Riedel, H, 1987, Fracture at High Temperatures, Springer-Verlag Berlin, Heidelberg.

[19] Rice, J.R., 1968, Mathematical analysis in the mechanics of fracture, in Treatise on Fracture (ed. H. Liebowitz), vol. 2, Academic Press, New York.

[20] ASTM E1457-01, 'Standard test method for measurement of creep crack growth rates in Metals', 2002.

[21] Nikbin, K.M., Smith, D.J. and Webster, G.A., 'Advances in life prediction methods at elevated temperatures', Conf. Proc. ASME 1983; 183-197. 
[22] Nikbin, K.M., Smith, D.J. and Webster, G.A. 'An engineering approach to the prediction of creep crack growth', J. of Engineering Materials and technology 1986; 108, 186-191.

[23] Tan, M., Celard, N.J.C., Nikbun, K.M. and Webster, G.A., 2001, 'Comparison of creep crack initiation and growth in four steels tested in HIDA', Int. J. Pres. Vess. and Piping., 78, 737-747.

[24] Rice, J.R. and Tracey, D.M., 'On the Ductile Enlargement of Voids in Triaxial Stress Fields', J. Mech. Phys. Solids, 1969; 17, 201-217.

[25] Spindler, M.W., 1994.' 'The Multiaxial Creep of Austenitic Stainless Steels', Nuclear Electric Report TIGM/REP/0014/94.

[26] ABAQUS version 5.8, 1998. Hibbitt, Karlsson \& Sorensen, Inc.

[27] LICON, Draft Code of Practice, EU FP5- Collaborative Programme on Accelerated damage Testing in Advenaced steels', June 2001.

[28] Kanninen, M.F. and Popelar, C.H., 1985, Advanced Fracture Mechanics, Oxford University Press, New York. 
Table 1: Chemical composition of C-Mn steel

\begin{tabular}{|l|c|c|c|c|c|c|c|c|c|c|c|c|}
\hline & C & Si & Mn & P & S & Cr & Mo & Ni & Cu & Al & N & FN \\
\hline High FN content C-Mn steel & 0.16 & 0.28 & 0.87 & 0.014 & 0.014 & 0.09 & 0.05 & 0.2 & 0.15 & 0.019 & 0.019 & 0.0110 \\
\hline
\end{tabular}

${ }^{\dagger} \mathrm{FN}$ is calculated "free nitrogen" at $920^{\circ} \mathrm{C}$ for all materials

Table 2: Material constants for the high nitrogen C-Mn steel at $360^{\circ} \mathrm{C}$ (for $A_{A}$ and $n_{A}$, stress is in MPa and time in hours)

\begin{tabular}{|c|c|c|c|c|}
\hline Temperature & Young's modulus & $\sigma_{\mathrm{y}}$ & $A_{A}$ & $n_{A}$ \\
\hline $360^{\circ} \mathrm{C}$ & $190 \mathrm{Gpa}$ & $240 \mathrm{MPa}$ & $1.78 \times 10^{-30}$ & 10.0 \\
\hline
\end{tabular}

Table 3: FE analyses conducted in section 4

\begin{tabular}{|c|c|c|c|c|}
\hline Section & Crack growth Model & Mesh size & Plasticity & Failure strain, $\varepsilon_{f}$ \\
\hline \multirow[t]{2}{*}{4.1} & Fixed-node model & \multirow[t]{2}{*}{ Coarse mesh } & \multirow[t]{2}{*}{ No } & \multirow[t]{2}{*}{$18 \%$} \\
\hline & Node-release model & & & \\
\hline \multirow[t]{4}{*}{4.2} & \multirow{4}{*}{ Node-release model } & \multirow[t]{2}{*}{ Coarse mesh } & No & \multirow[t]{4}{*}{$18 \%$} \\
\hline & & & Yes & \\
\hline & & Fine mesh & No & \\
\hline & & & Yes & \\
\hline \multirow[t]{2}{*}{4.3} & \multirow[t]{2}{*}{ Node-release model } & \multirow[t]{2}{*}{ Fine mesh } & No & \multirow[t]{2}{*}{$50 \%$} \\
\hline & & & Yes & \\
\hline 4.4 & Node-release model & Fine mesh & Yes & $18 \%$ \\
\hline \multirow[t]{4}{*}{4.5} & \multirow[t]{4}{*}{ Node-release model } & \multirow[t]{4}{*}{ Fine mesh } & \multirow[t]{4}{*}{ Yes } & $10 \%$ \\
\hline & & & & $18 \%$ \\
\hline & & & & $26 \%$ \\
\hline & & & & $50 \%$ \\
\hline
\end{tabular}




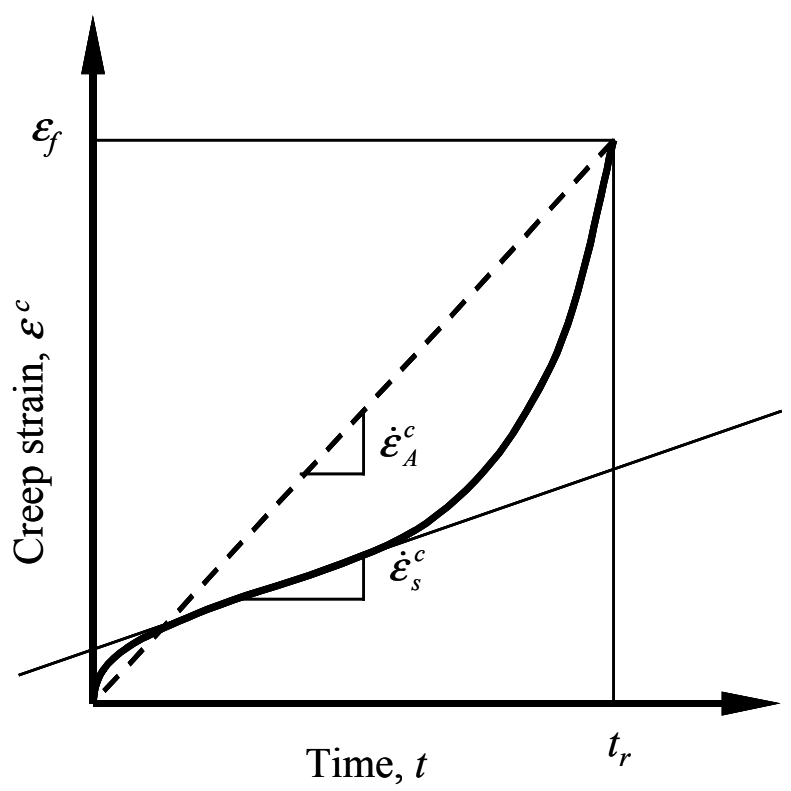

Figure 1: Schematic creep curve illustrating secondary creep rate, $\dot{\varepsilon}_{A}^{c}$, and average creep rate $\dot{\varepsilon}_{A}^{c}$

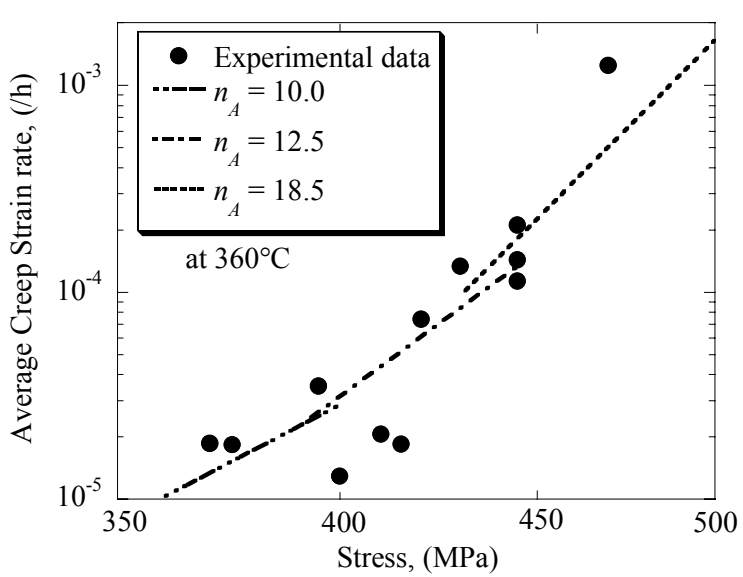

Figure 2: Average creep strain rate versus stress for C-Mn at $360^{\circ} \mathrm{C}$

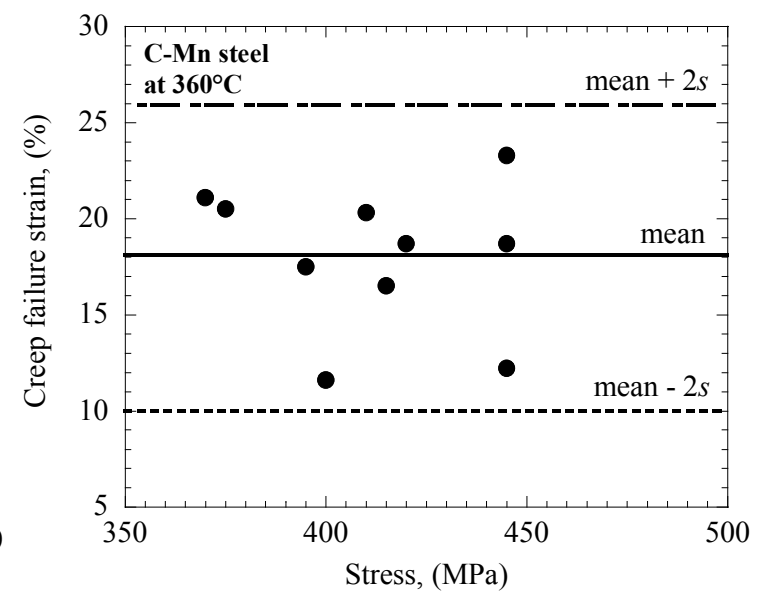

Figure 3: Creep ductility for C-Mn steels at $360^{\circ} \mathrm{C}$, including mean and $\pm 2 s$ lines 


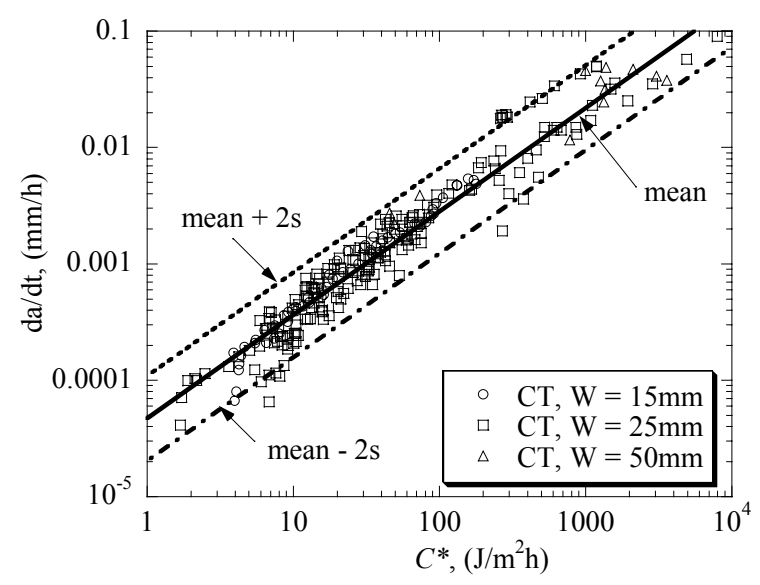

Figure 4: Steady state creep crack growth versus $C^{*}$ for the C-Mn steel at $360^{\circ} \mathrm{C}$ showing the bounds for $\pm 2 \mathrm{~s}$

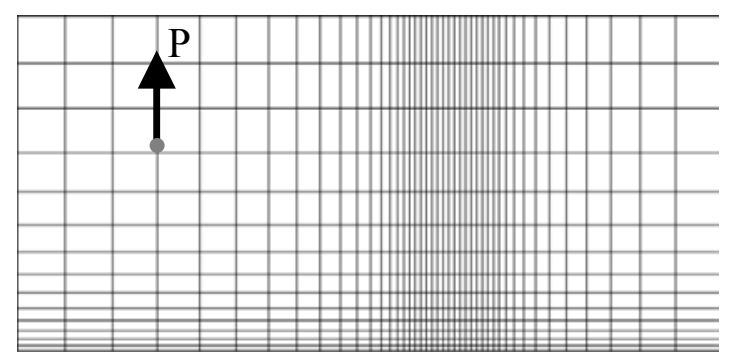

(a)

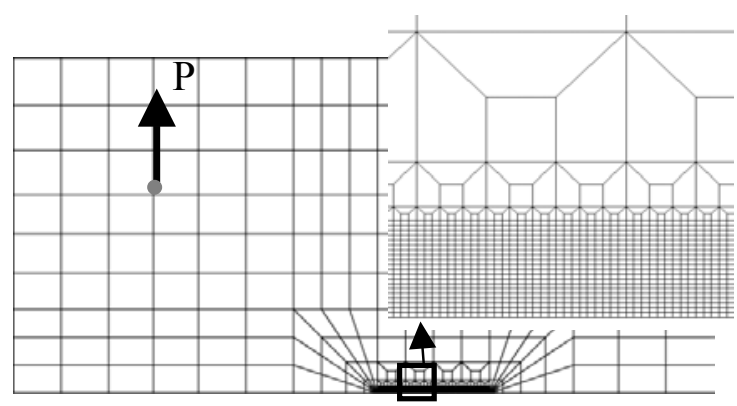

(b)

Figure 5: FE mesh for CCG analysis of CT specimen (a) coarse mesh and (b) fine mesh
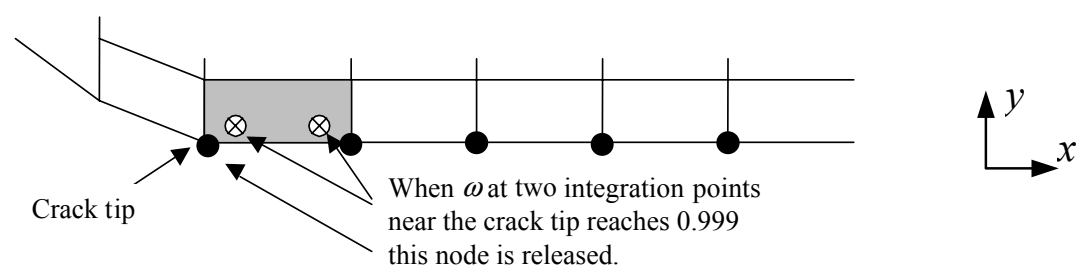

Figure 6: Schematic illustration of crack growth using the nodal release method. 


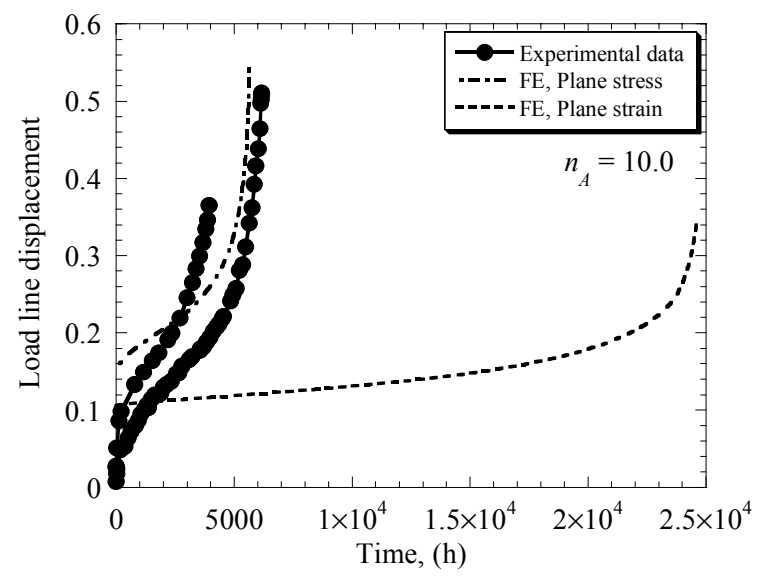

Figure 7: Comparison of experimental load- line displacement from two tests with the FE analysis for a $\mathrm{CT}$ specimen under plane stress and plane strain conditions

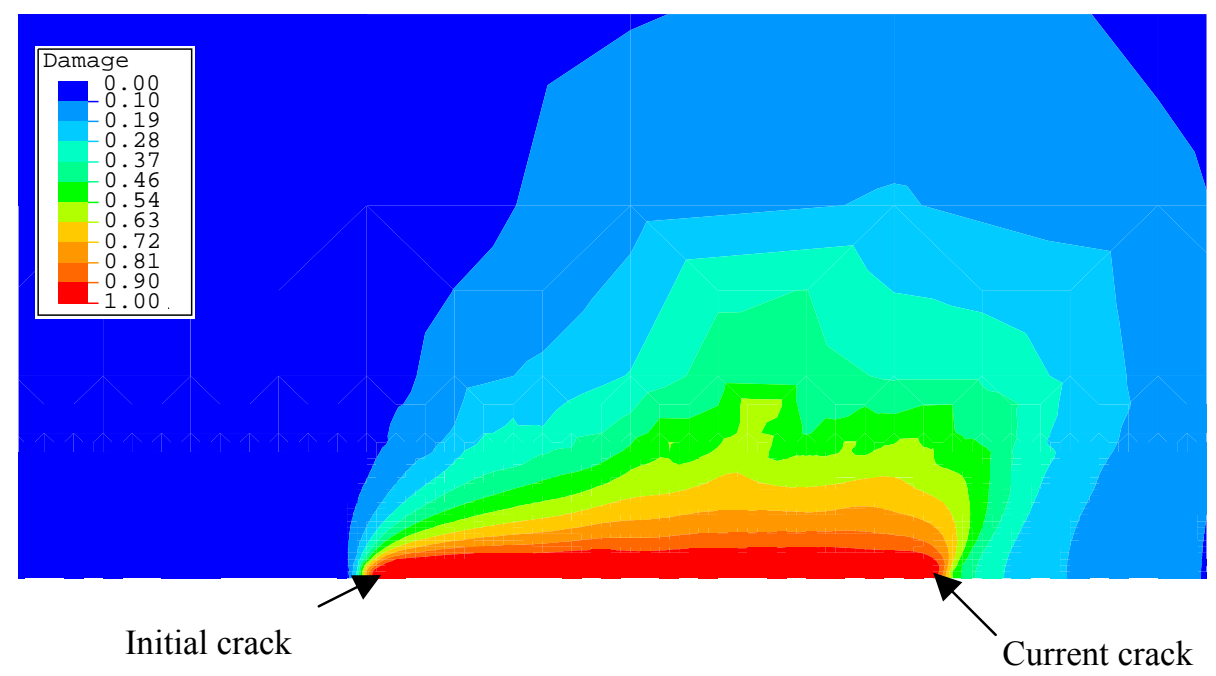

Figure 8: Damage contour plot for an elastic-creep analysis of a CT mesh using the noderelease model 
(a)

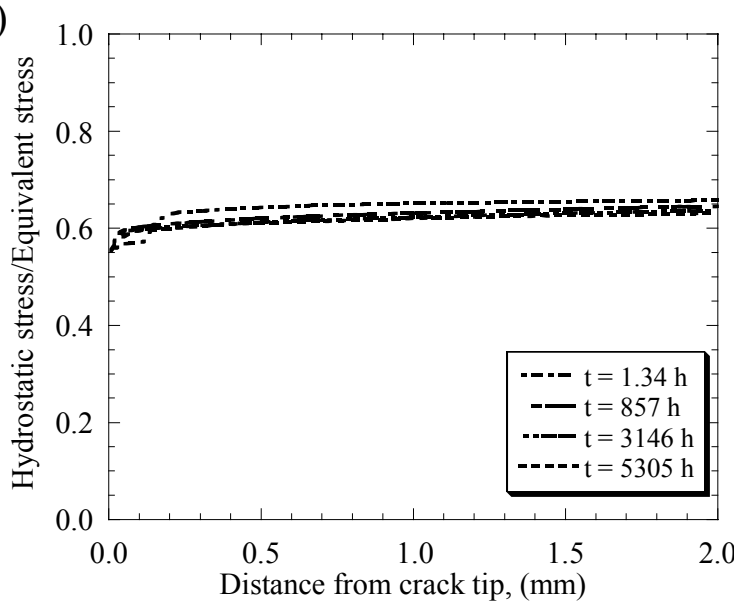

(b)

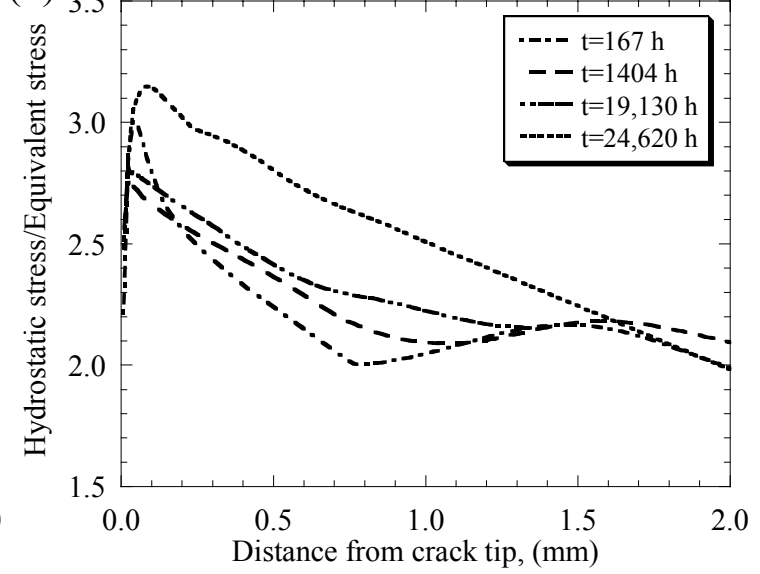

Figure 9: Triaxiality $\sigma_{m} / \sigma_{e}$ plotted against distance from the crack tip for the CT specimen for four different times (a) plane stress (b) plane strain 

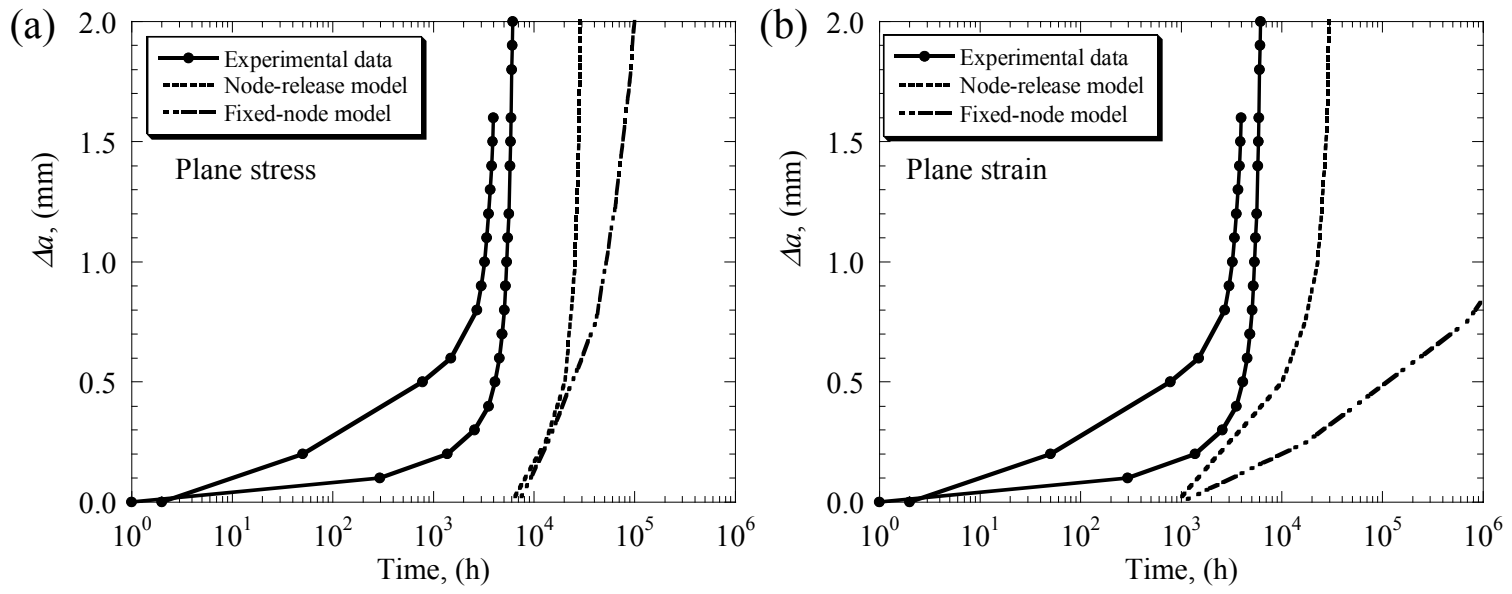

Figure 10: Predicted crack growth against time for node-release and fixed-node models (a) plane stress, (b) plane strain.
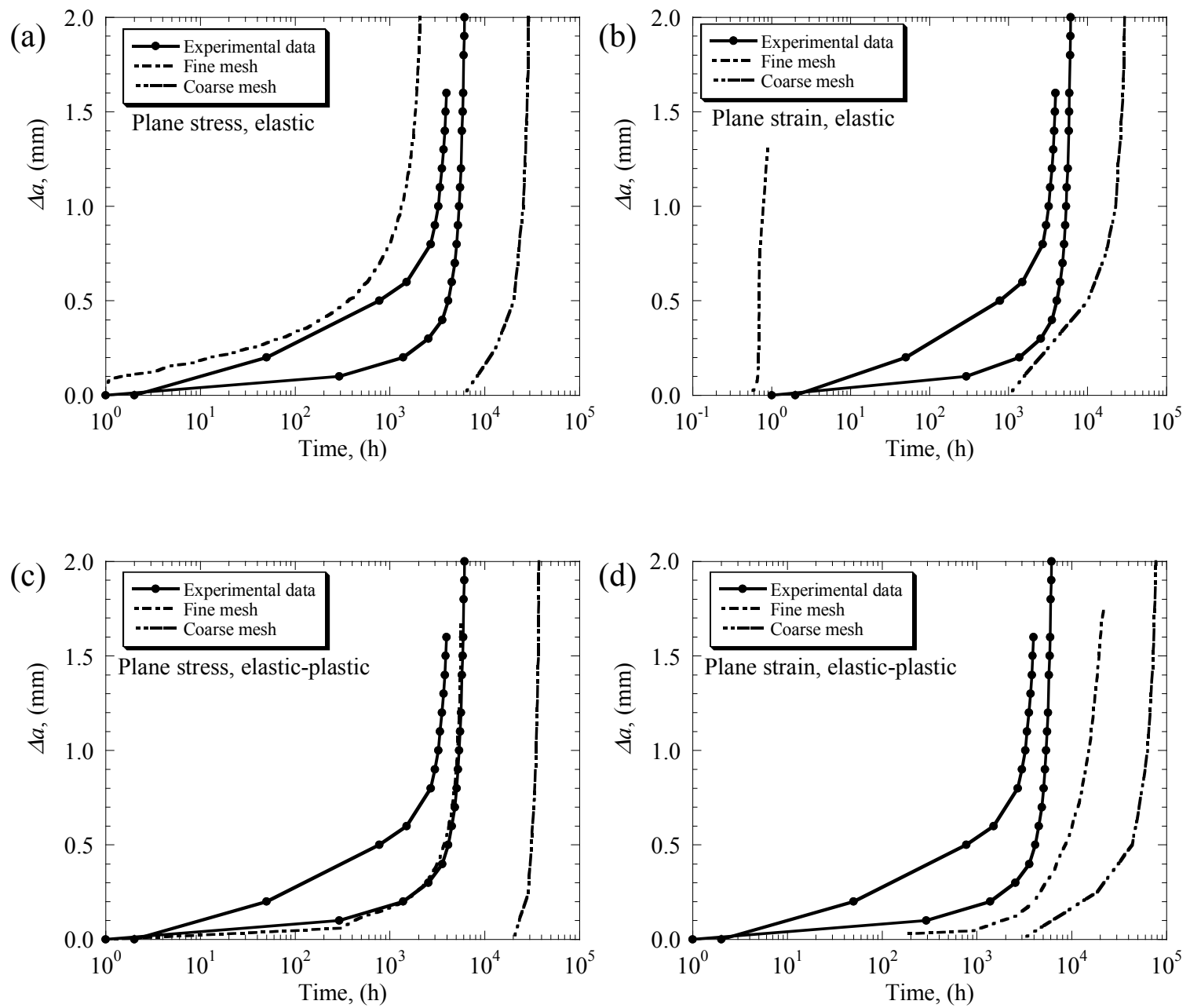

Figure 11: Effect of mesh size on predicted CCG (a) plane stress, elastic analysis, (b) plane strain, elastic analysis (c) plane stress, elastic-plastic analysis, (d) plane strain, elastic-plastic analysis 


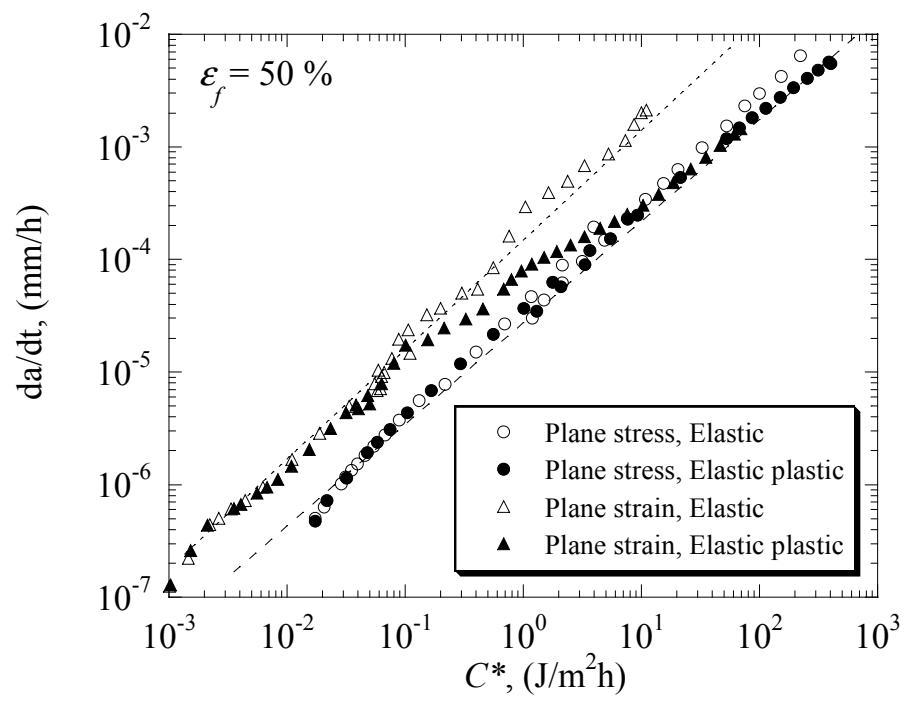

Figure 12: Prediction of CCG rate against $C^{*}$. The dotted lines are the mean lines through the elastic plane strain and elastic or elastic plastic plane stress analyses.

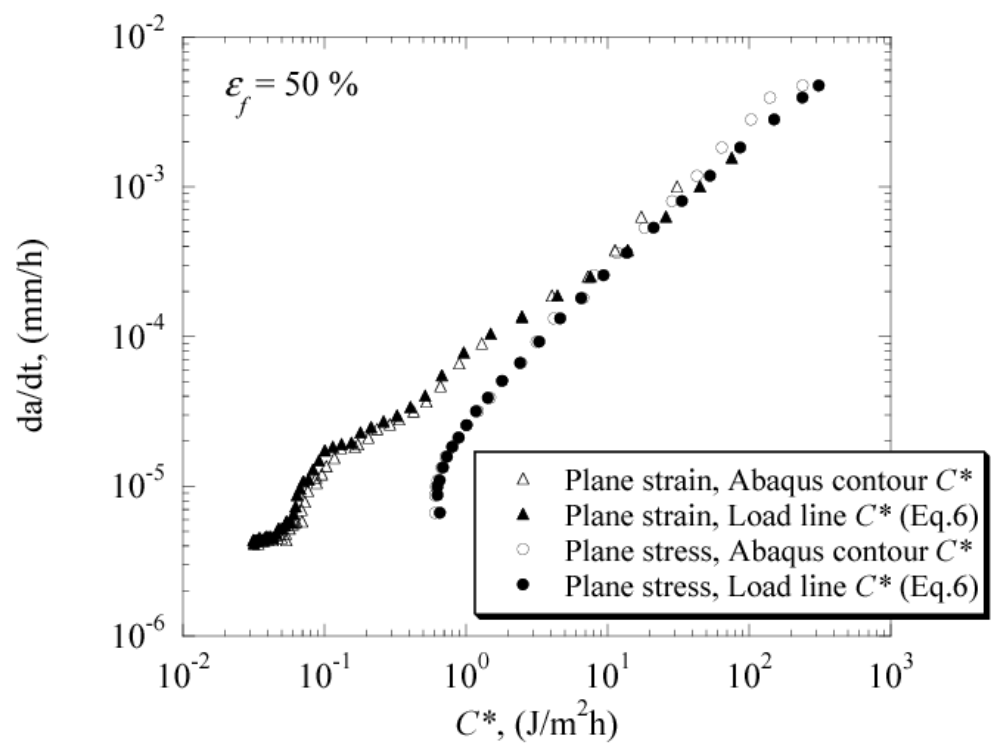

Figure 13: CCG rate plotted against $C^{*}$ using the contour integral and load line displacement rate definitions 


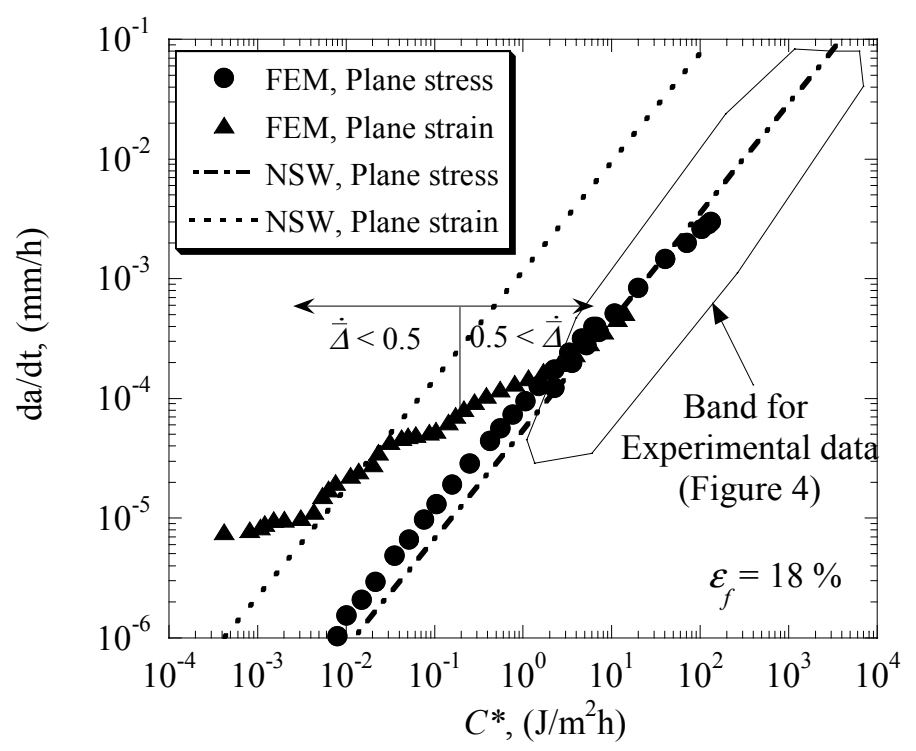

Figure 14: Comparison of predicted CCG rate and experimental data for C-Mn steel. Arrows indicates creep brittle/ductile bound [20] 
(a)

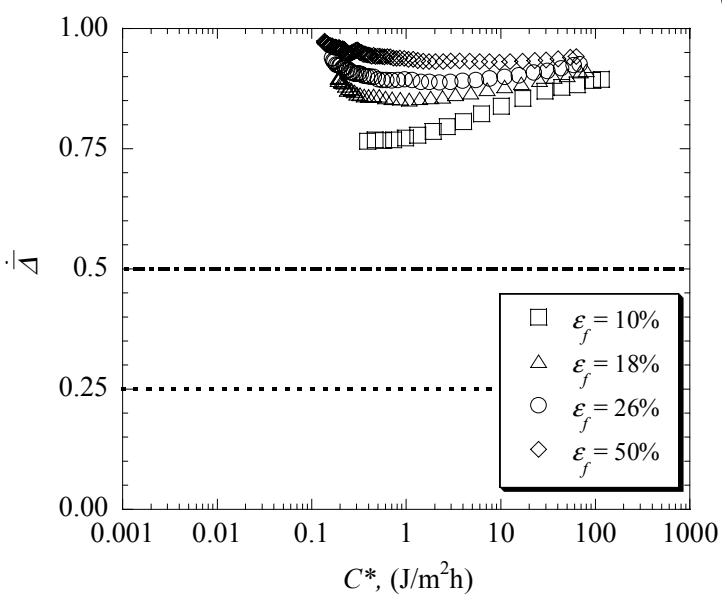

(b)

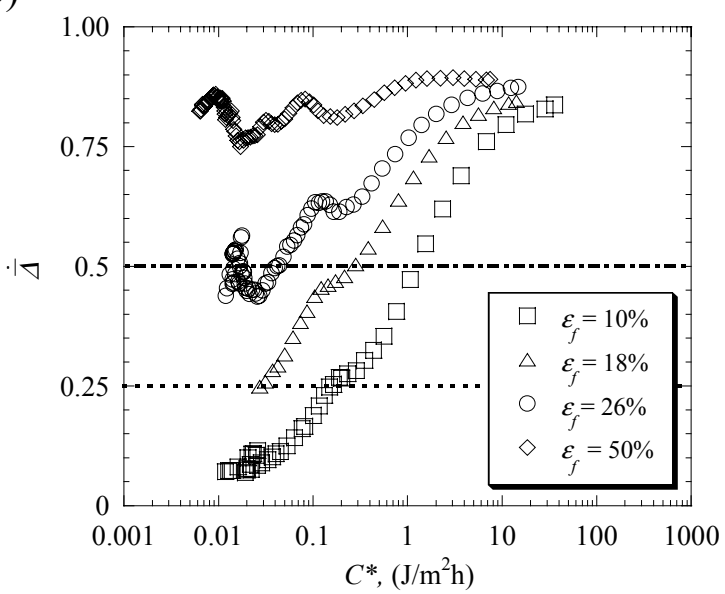

Figure 15: $\dot{\bar{\Delta}}\left(=\dot{\Delta}^{c} / \dot{\Delta}^{T}\right)$ plotted against $C^{*}$ for a range of failure strains, (a) plane stress (b) plane strain
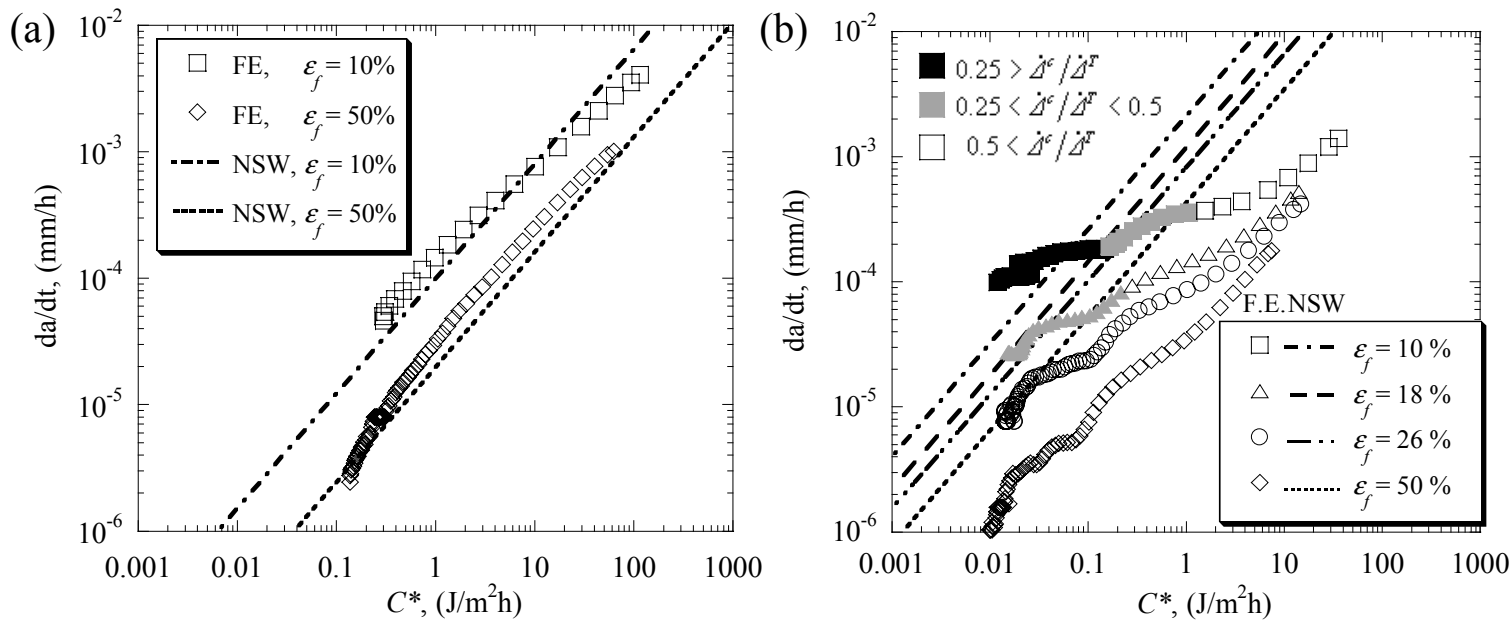

Figure 16: Effect of creep ductility $\mathcal{E}_{f}$ on CCG rate (a) plane stress elastic-plastic analysis, (b) plane strain elastic-plastic analysis. 